\title{
Sistem Pendeteksi Kebocoran Gas Menggunakan Sensor MQ-6 Berbasis Jaringan Sensor Wireless
}

Gas Leak Detection System Using MQ-6 Based On Wireless Sensor Network

\author{
Imam Hidayat \\ Teknik Informatika, Universitas Muhammadiyah Malang \\ Jl. Raya Tlogomas No. 246, Malang, 65144, Indonesia. \\ E-mail: hidayatimam69@gmail.com
}

\begin{abstract}
Abstrak
Pemakaian gas LPG dapat membantu memudahkan kegiatan masak memasak dan memperlancar bisnis masyarakat yang menggunakannya. Terlepas dari kegunaannya bagi masyarakat, gas LPG juga menyimpan bahaya yang mengancam. Hal tersebut dikarenakan jika terjadi kebocoran gas pada LPG tersebut. Penyebab dari bocor tabung gas ini bisa terjadi karena kebocoran pada selang, tabung atau pada regulatornya yang tidak terpasang dengan baik dan tabung gas yang didistribusikan memang kualitasnya kurang baik atau rusak fisik. Penelitian ini bertujuan untuk menghasilkan sebuah rancang bangun alat pendeteksi kebocoran tabung gas LPG dengan menggunakan sensor MQ-6 sebagai sensor gas, dan GSM Modul sebagai pengirim notifikasi sms ke ponsel pengguna, Arduino Uno sebagai penghubung berbagai sistem dan berbagai alat lainnya. Cara kerja alat ini yaitu, ketika sensor MQ-6 mendeteksi gas LPG maka sensor akan mengirimkan data ke Arduino kemudian Arduino mengirimkan instruksi ke GSM Modul untuk mengirimkan pesan notifikasi pada ponsel pengguna.
\end{abstract}

Kata kunci-gas LPG, Arduino, pendeteksi kebocoran gas, jaringan sensor wireless, sms

\begin{abstract}
The use of LPG gas can help facilitate cooking activities and facilitate business community who use it. Apart from its usefulness to the community, LPG gas also keeps a threatening danger. This is because if there is a gas leak in the LPG. The cause of leakage of this gas cylinder can occur due to leakage in hoses, tubes or on the regulator that is not installed properly and the gas tubes are distributed are not good quality or physical damage. This research aims to produce a design of LPG gas leak detection equipment using MQ-6 sensor as gas sensor, and GSM Module as sender of sms notification to user's mobile phone, Arduino Uno as connector of various system and various other tools. The way this tool works is that when the MQ-6 sensor detects LPG gas the sensor will send data to Arduino then Arduino sends instructions to GSM Module to send notification messages on the user's mobile phone.
\end{abstract}

Keywords - LPG, Arduino, gas leak detector, wireless sensor network, sms

\section{PENDAHULUAN}

Dewasa ini kebutuhan masyarakat Indonesia akan energi dan sumber daya alam semakin meningkat pesat. Semakin meningkatnya kebutuhan akan energi mendorong adanya penghapusan subsidi minyak tanah oleh pemerintah sehingga kini masyarakat beramai-ramai beralih untuk menggunakan tabung gas LPG (Liquefied Petroleum Gas). Program sosialisasi penggunaan gas LPG oleh pemerintah ini sudah dilakukan sejak tahun 2007 dengan harapan dapat memenuhi kebutuhan dan dapat dijangkau oleh seluruh lapisan masyarakat[1].

Namun belakangan ini semakin marak terjadinya kasus-kasus ledakan akibat dari minimnya pengetahuan dan keamanan dalam penggunaan gas LPG. Kebocoran tabung atau perangkat LPG sampai saat ini masih menjadi salah satu penyebab utama kebakaran[1]. Gas 
LPG yang mengalami kebocoran memang tercium baunya sehingga kebocoran normal mudah dideteksi. Gas LPG yang mengalami kebocoran memang tercium baunya sehingga kebocoran normal mudah dideteksi. Akan tetapi, bila gas yang bocor meresap kedalam saluran air, instalansi listrik, atau ke bawah karpet, maka akan sulit di deteksi oleh indra penciuman manusia[2]. Berdasarkan adanya kasus semacam ini, maka dibutuhkan adanya suatu sistem yang mampu menjadi pengingat, pemberitahu dan pencegah adanya bahaya buruk yang diakibatkan oleh adanya kebocoran gas LPG.

Pada penelitian sebelumnya tentang "Rancang Bangun Alat Pendeteksi Kebocoran Gas Lpg Dengan Sensor Mq-6 Berbasis Mikrokontroler Melalui Smartphone Android Sebagai Media Informasi” juga membahas tentang hal yang sama, dimana luaran yang didapat dari penelitian tersebut adalah sistem pendeteksi kebocoran gas dengan memanfaatkan Mikrokontroler yang menggunakan ponsel pintar sebagai media informasi. Secara umum, sistem yang dirancang memiliki persamaan. Namun dalam pemilihan pemanfaatan media dan teknologi terdapat perbedaan yaitu menggunakan jaringan sensor nirkabel dengan menggunakan sms sebagai media informasi[2].

Penelitian lainnya juga pernah membahas kajian yang sama, yaitu penelitian yang dilakukan oleh Bambang Eko Soemarsono pada tahun 2015 tentang "Alat Pendeteksi Dini Terhadap Kebocoran Gas LPG”. Luaran dari penelitian ini adalah alat detector gas yang mampu memberikan sms ke pihat terkait jika adanya kebocoran gas. Dalam pengerjaannya, penelitian ini memanfaatkan teknologi Mikrokontroler[3].

Dari beberapa penelitian sebelumnya, penulis tertarik untuk membuat suatu sistem yang mampu menjadi pengingat dan mampu memonitoring langsung terkait adanya kebocoran gas dengan memanfaatkan teknologi jaringan sensor nirkabel dan short message service sebagai media pemberi informasi. Pada penelitian sebelumnya sistem dibangun menggunakan Mikrokontroler, Arduino dan lain sebagainya. Perbedaan yang terdapat pada penelitian ini dari penelitian sebelumnya ialah sistem yang akan dibangun memanfaatkan jaringan sensor nirkabel dan penggunaan sms sebagai media informasi. Pada sistem ini juga akan digunakan sensor MQ6 sebagai pendeteksi adanya bau gas yang bocor, arduino uno yang bertindak sebagai otak dari sistem, GSM Modul yang akan mengirimkan sms peringatan kepada ponsel, dan juga berbagai alat yang dibutuhkan lainnya.

\section{METODE PENELITIAN}

Dalam penyusunan penelitian ini, penulis menggunakan beberapa langkah atau metode, antara lain: 


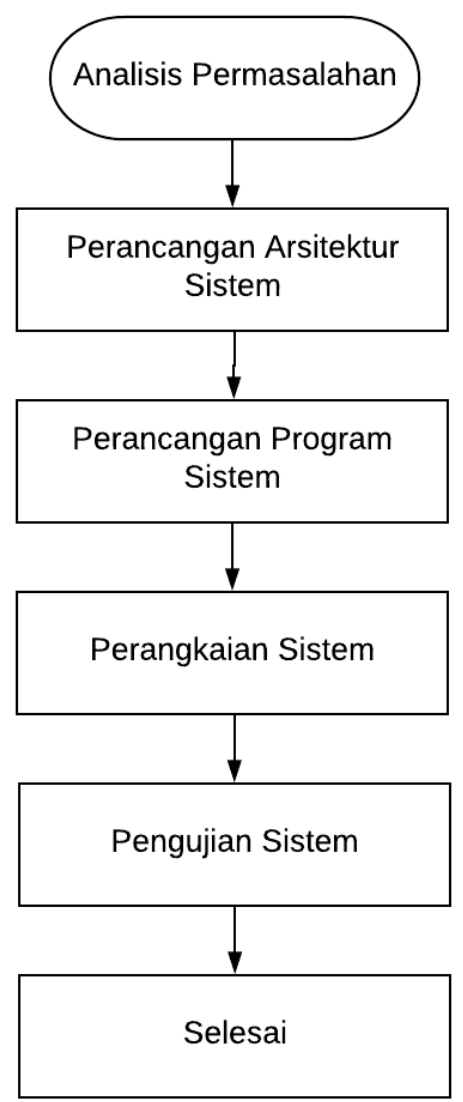

Gambar 1. Metode Penelitian

\subsection{Analisis Permasalahan}

Penggunaaan gas elpiji yang semakin membludak memang memudahkan kehidupan masyarakat. Segala kegiatan industri yang menggunakan gas dalam pelaksanaannya semakin termudahkan. Namun suatu yang memudahkan dan praktis tentu tidak terlepas dari bahaya. Banyak terjadi kasus ledakan dan keracunan akibat dari kebocoran gas elpiji. Penggunaan yang tidak hati-hati membuat gas mudah bocor dan membahayakan. Kebocoran gas elpiji juga begitu sulit dideteksi, apalagi jika ditempatkan dalam ruangan yang bising. Dari masalah ini, penulis bermaksud membuat suatu sistem untuk melakukan pendeteksian terhadap kebocoran gas dengan mengirimkan notifikasi sms sebagai bentuk pesan peringatan kepada pengguna.

\subsection{Perancangan Arsitektur Sistem}

Adapun sistem kerja yang dirancang adalah sensor MQ-6 diletakan berdekatan dengan gas dengan jarak kira-kira $30 \mathrm{~cm}$ untuk memudahkan sensor mendeteksi adanya kebocoran gas LPG. Jika terdeteksi adanya kebocoran gas, maka sensor MQ-6 akan mengirimkan data kepada Arduino Uno bahwa telah terdeteksi kebocoran gas. Arduino Uno kemudian memberikan instruksi berupa perintah untuk mengirimkan notifikasi sms pada GSM Modul. GSM Modul selanjutnya mengirimkan pesan notifikasi kepada ponsel pengguna. Kemudian ponsel akan menerima pesan peringatan kebocoran gas. 


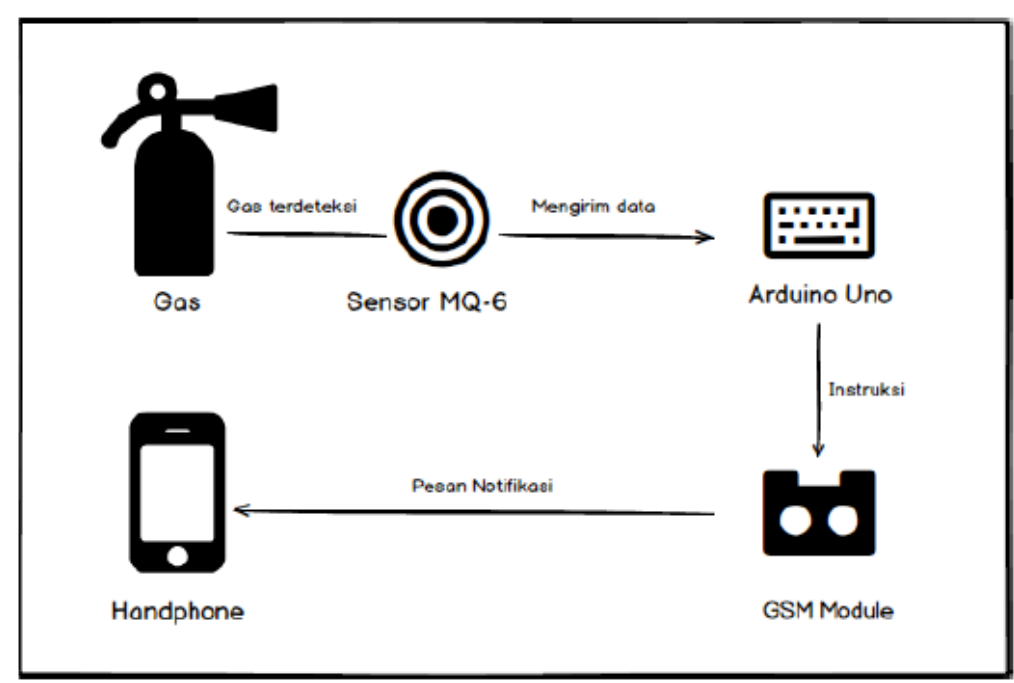

Gambar 2. Arsitektur Sistem

\subsection{Perancangan Program Sistem}

Dalam membangun sistem kebocoran gas ini, penulis menggunakan bahasa pemrograman C. Dalam program ini juga digunakan library GSM Shield. Sistem pendeteksi kebocoran gas ini menggunakan compiler Arduino IDE. Program yang dibuat berdasarkan pada flowchat berikut.

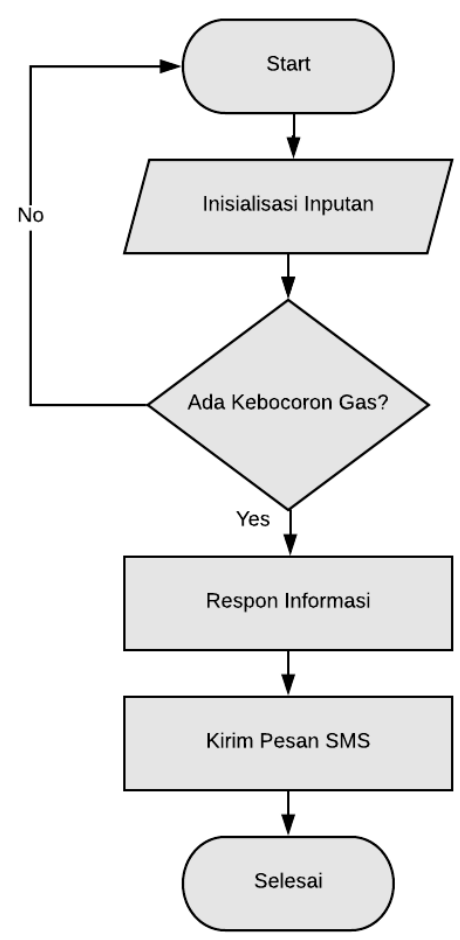

\subsection{Perangkaian Sistem}

Gambar 3. Flowchart Sistem

Setelah ketiga tahap diatas dilakukan, maka selanjutnya dilakukan perangkaian sistem. Perangkaian sistem ini bermaksud agar semua alat saling terhubung dan berkoneksi antara satu dengan lainnya sehingga bisa berjalan seperti apa yang diinginkan. Dalam perangkaian ini dilakukan implementasi dari arsitektur yang telah dibuat sebelumnya. Alat dan bahan yang 
dibutuhkan dalam melakukan perangkaian sistem pendeteksi kebocoran gas ini adalah sensor MQ-6, Arduino Uno, Relay, Jumper, GSM Modul SIM900, SIM card, dan berbagai alat lain yang dibutuhkan. Setiap bagian harus diperhatikan agar bisa saling bekerja dan terhubung. Perangkaian sistem merupakan salah satu tahap penting untuk mendapat hasil penelitian ini.

\subsection{Pengujian}

Pengujian dilakukan dengan tujuan untuk mengetahui apakah data yang dihasilkan sesuai dengan apa yang diharapkan sehingga bisa dipertanggung jawabkan kebenarannya. Pada penelitian ini, pengujian menggunakan korek api gas atau pemantik. Korek api gas adalah korek api yang menggunakan cairan seperti naphtha atau butana. Sehingga gas semacam ini bisa dideteksi oleh sensor MQ-6.

\section{HASIL DAN PEMBAHASAN}

Untuk mengimplementasi setiap metode yang penelitian yang ada, dibuatlah sebuah rangkaian sistem pendeteksi kebocoran yang diprogram menggunakan bahasa pemrograman $\mathrm{C}$. Rangkaian sistem bertujuan agar sistem terlihat lebih terstruktur dan semua bagaian bisa dijalankan sebagaimana yang diharapkan. Rangkain tersebut dapat ditunjukan pada gambar berikut.

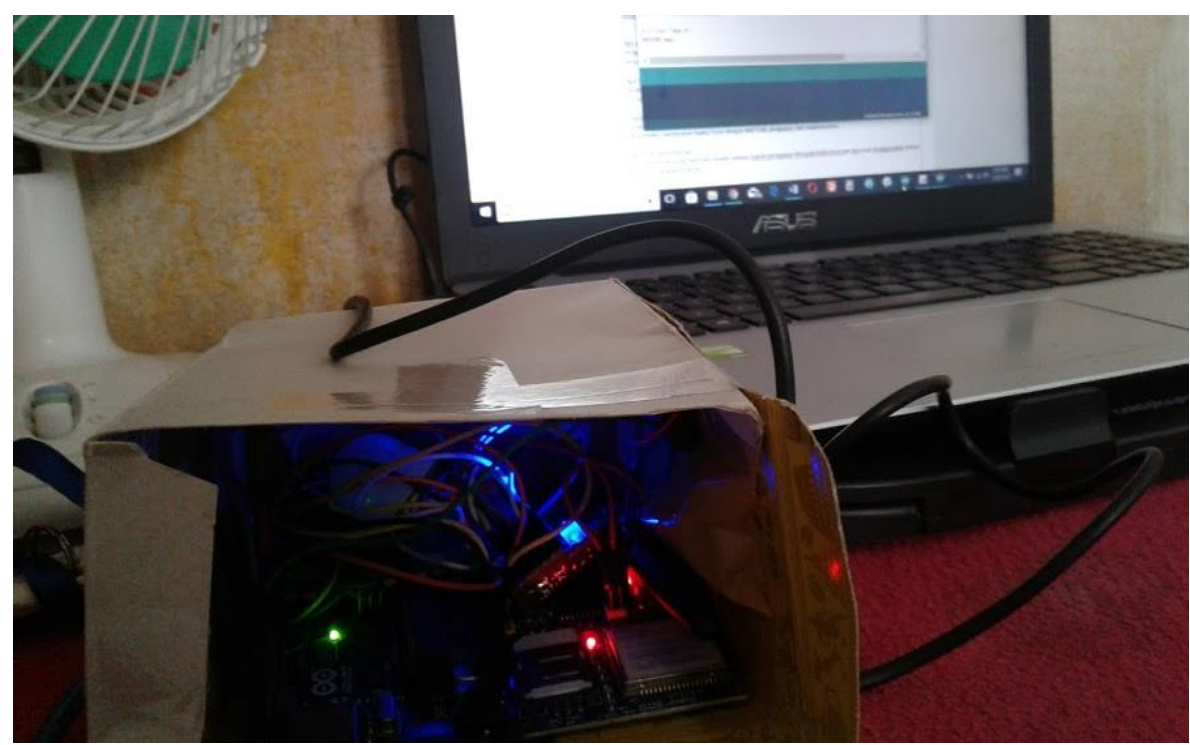

Gambar 4. Rangkaian Sistem 


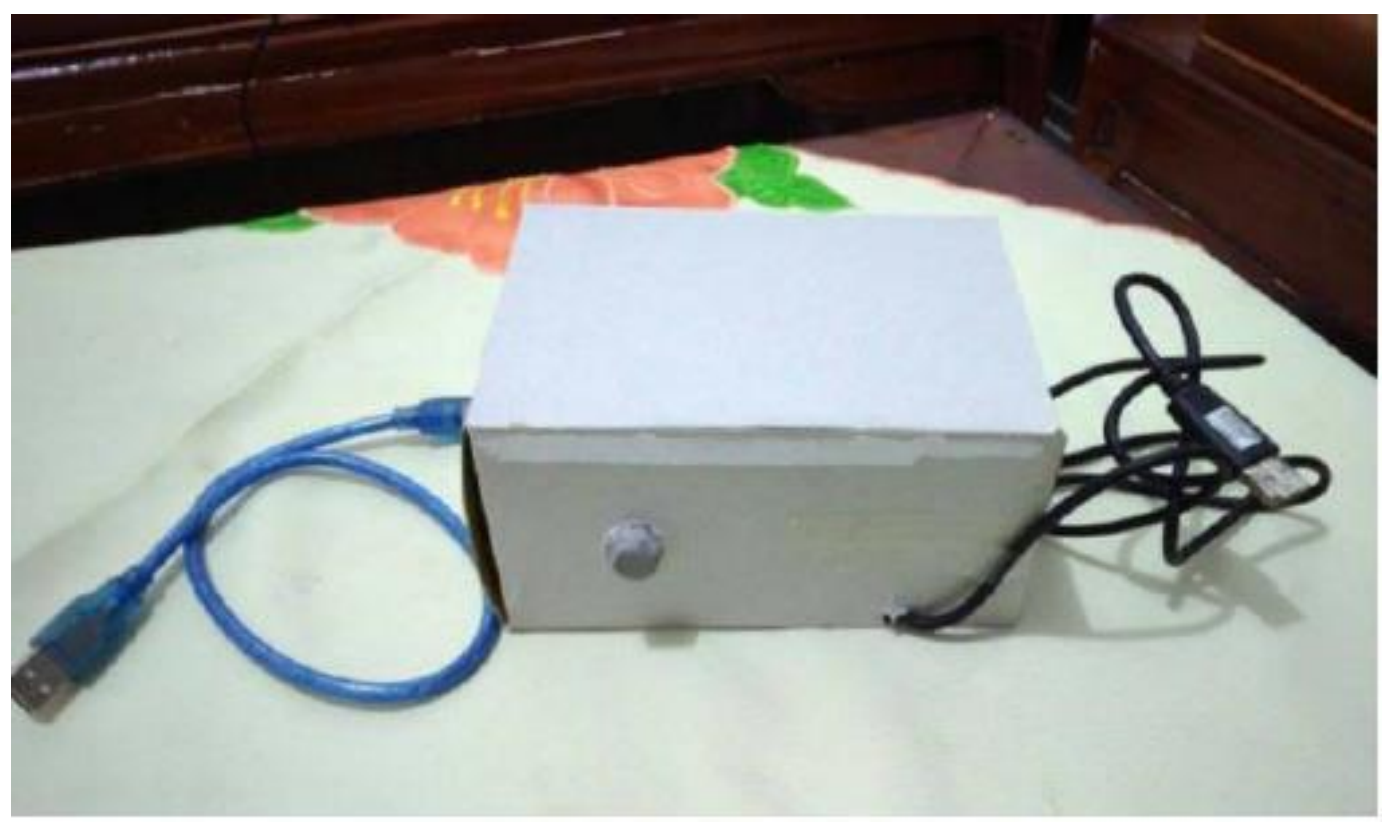

Gambar 5. Rangkaian Sistem

Setelah dilakukan perangkaian terhadap sistem, selanjutnya dilakukan pengujian. Pengujian ini dilakukan untuk membuktikan bahwa sistem berjalan sesuai dengan apa yang diinginkan.

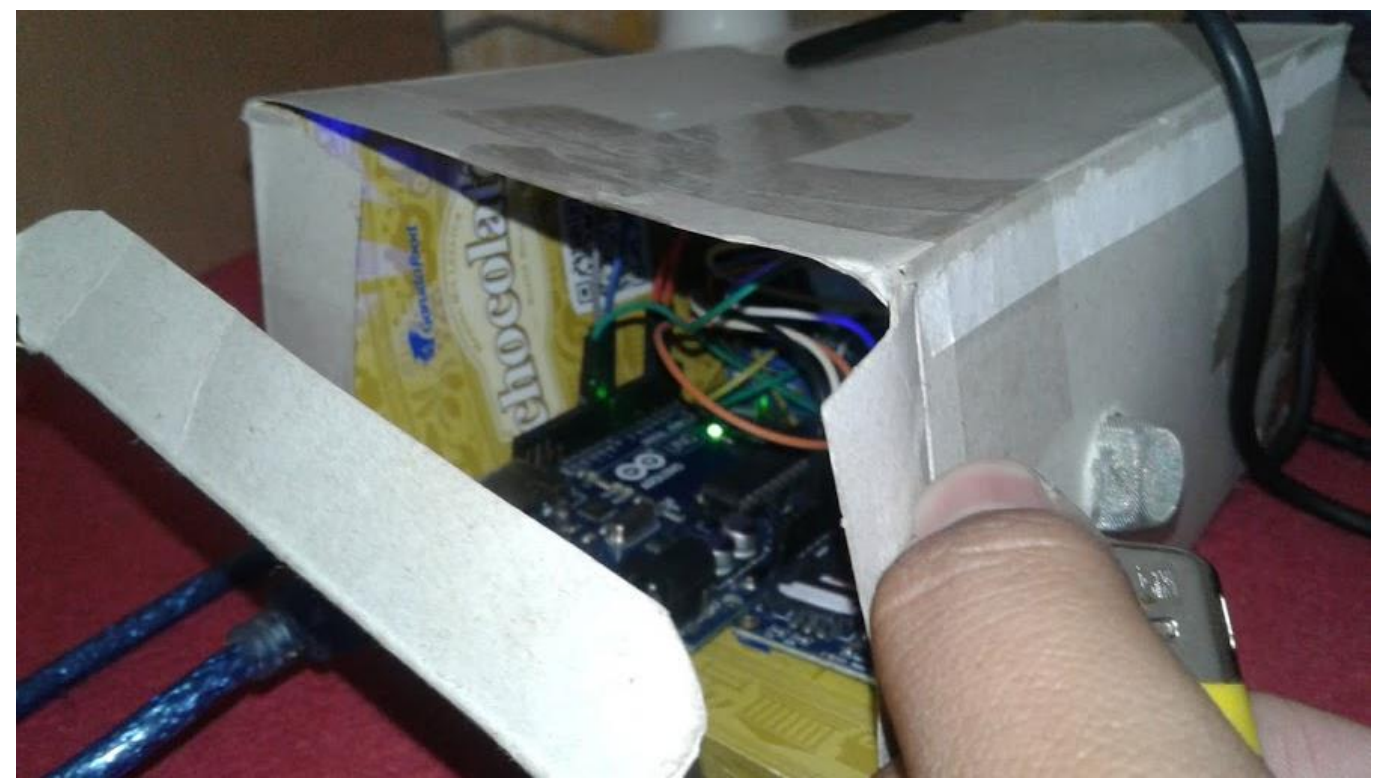

Gambar 6. Pengujian Sistem Menggunakan Pemantik

Untuk melihat seberapa tinggi gas pemantik yang dideteksi oleh sensor MQ-6, cukup dilakukan pengecekan terhadap Serial Monitor yang terdapat pada Arduino IDE. Untuk menampilkan Serial Monitor bisa melalui menu Tools ataupun menggunakan perintah CTRL+Shift+M. 


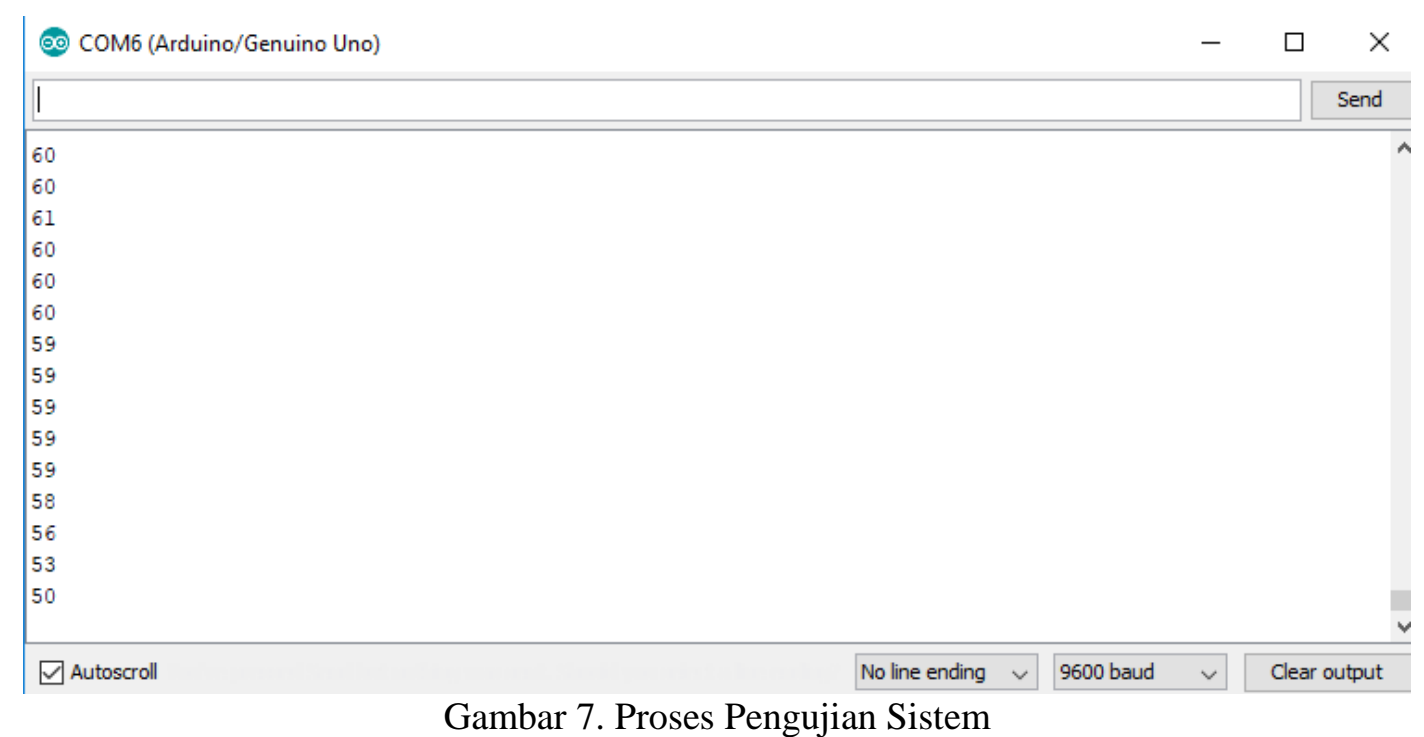

Dari tampilan Serial Monitor diatas dapat diketahui bahwa tingginya gas yang dideteksi masih dalam range 50 - 60. Hal tersebut berarti gas yang keluar dari pemantik masih kurang dan belum memenuhi batas minimal notifikasi dikirimkan. Untuk itu gas yang ada didalam pemantik harus dikeluarkan lagi sehingga memenuhi batas minimal sms dikirim. Apabila tinggi gas sudah memenuhi batas minimal, sms akan dikirimkan. Jika sms telah berhasil dikirim, maka akan muncul status "SMS Wes Dikirim" seperti yang ada dalam gambar berikut.

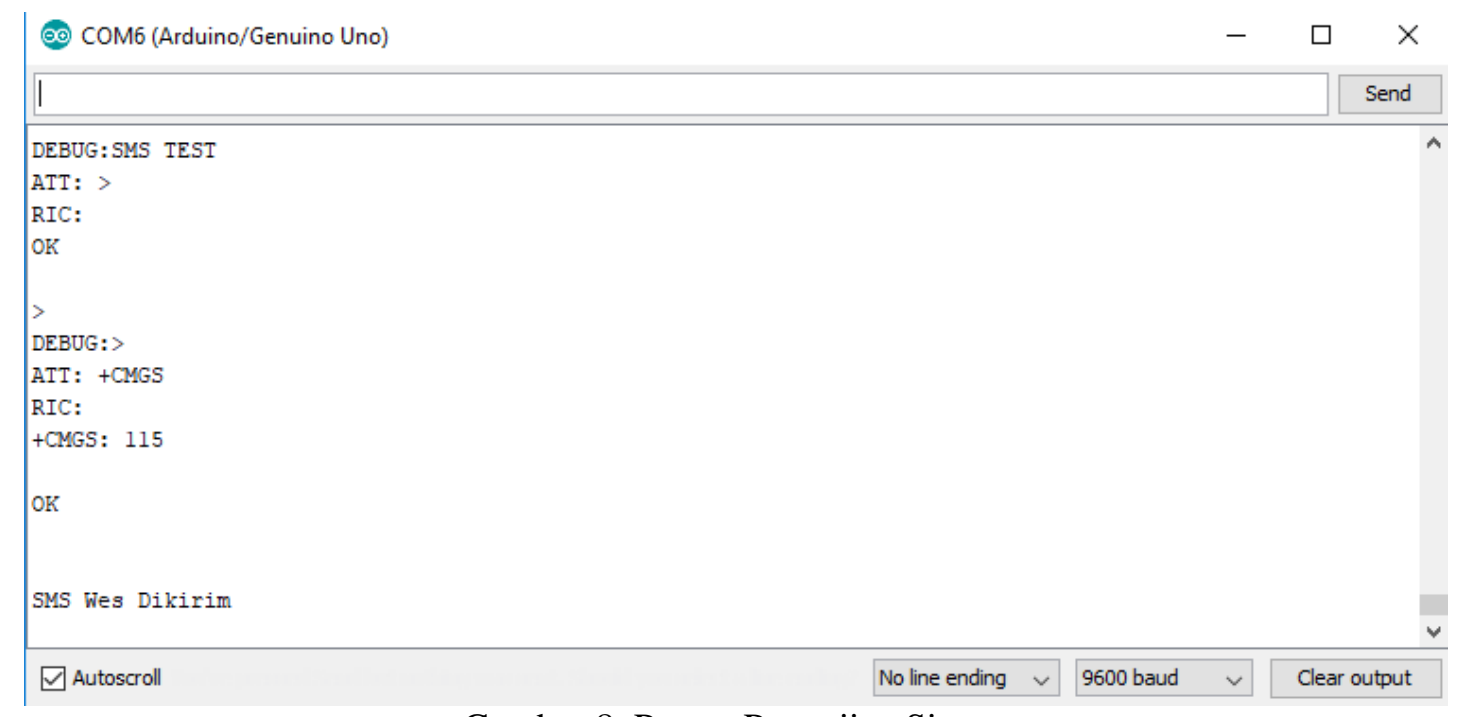

Gambar 8. Proses Pengujian Sistem

Setelah status sms pada Serial Monitor telah terkirim, maka akan masuk pesan notifikasi ke ponsel pengguna. Pengiriman pesan ini dilakukan kepada nomor ponsel yang sebelumnya telah dimasukan ke dalam kodingan sistem. Tampilan sms dari sistem bisa dilihat pada gambar berikut. 


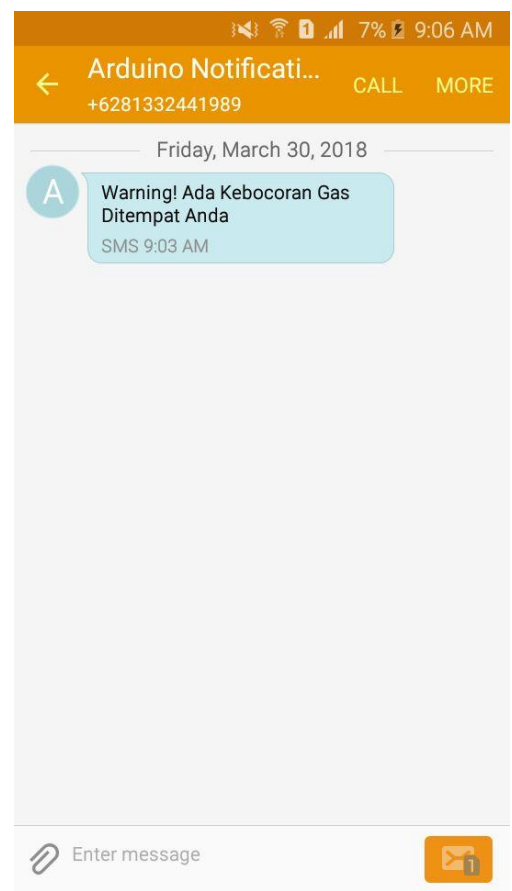

Gambar 9. Tampilan Notifikasi SMS Peringatan

Untuk lebih jelasnya, proses pengujian ini akan dituangkan kedalam beberapa tabel dan grafik. Berikut adalah tabel-tabel dan juga grafik-grafik pengujian sistem pedeteksi kebocoran gas.

Tabel 1. Tabel Pengujian

\begin{tabular}{|c|c|}
\hline Tinggi Gas Terdeksi & Notifikasi SMS \\
\hline 20 & Tidak Dikirim \\
\hline 50 & Tidak Dikirim \\
\hline 150 & Tidak Dikirim \\
\hline 350 & Dikirim \\
\hline 400 & Dikirim \\
\hline
\end{tabular}

Tabel 2. Tabel Logika Pengiriman Notifikasi

\begin{tabular}{|c|c|}
\hline Jika & Maka \\
\hline Gas $<350$ & Tidak Ada Notifikasi \\
\hline Gas $>349$ & Ada Notifikasi \\
\hline
\end{tabular}




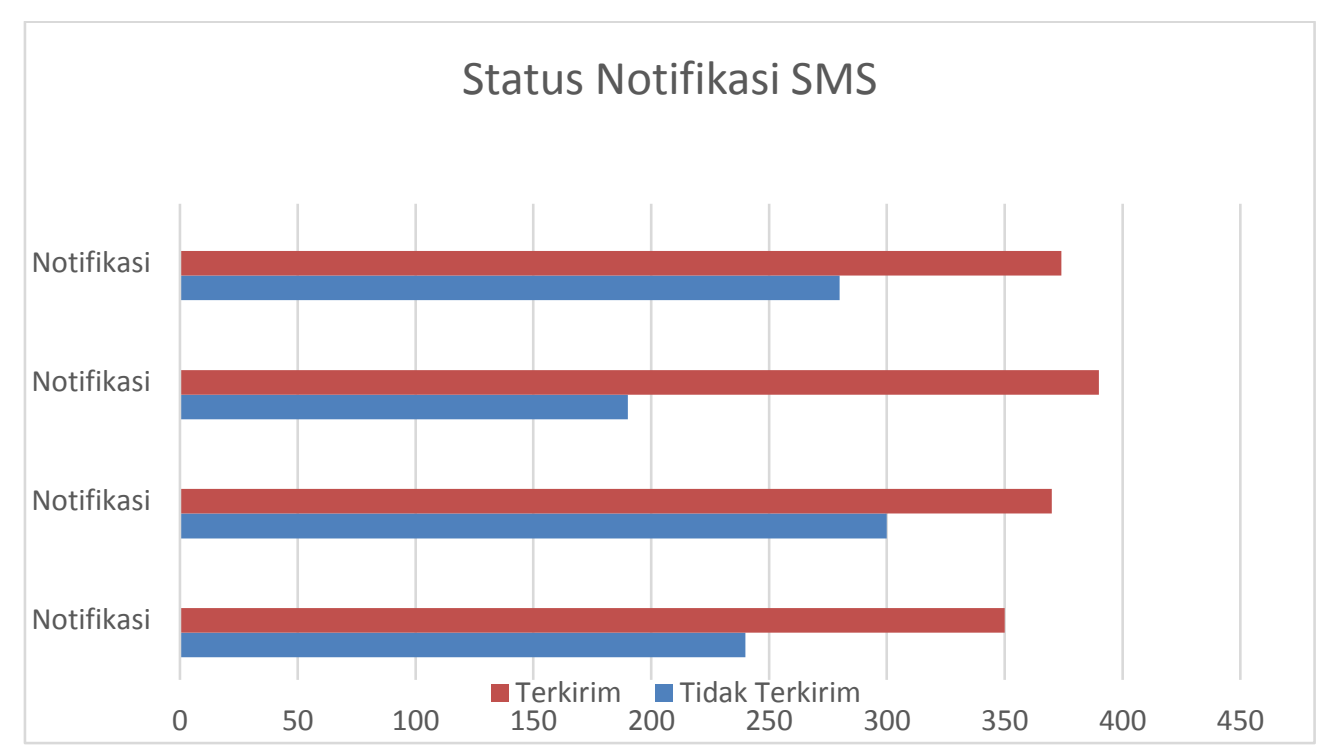

Gambar 10. Grafik Status Pengiriman Notifikasi SMS

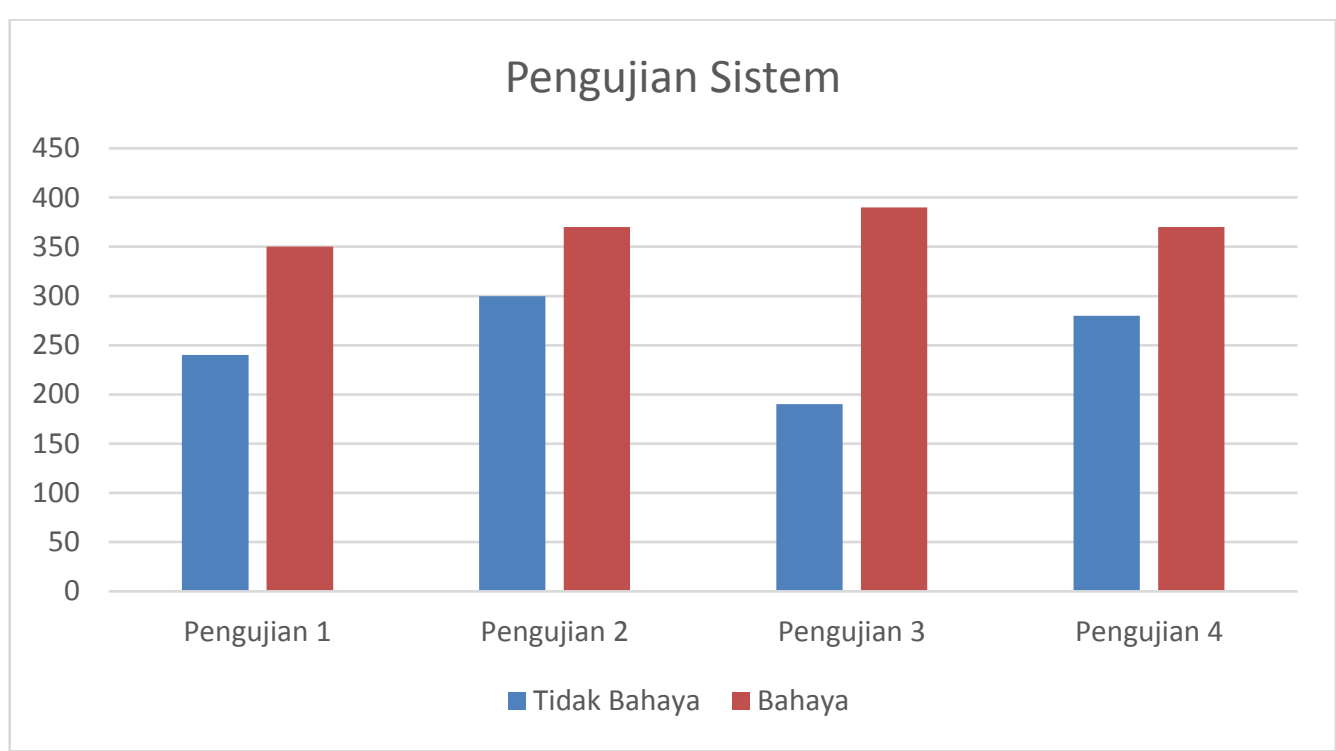

Gambar 11. Grafik Pengujian Sistem

Pengujian diatas dilakukan untuk mengetahui bagaimana sistem tersebut bekerja sesuai dengan apa yang diharapkan. Pada tabel pertama terdapat data mengenai tinggi gas terdeteksi dan notifikasi sms. Dari kedua variabel tersebut dapat diketahui bahwa semakin tinggi tingkat deteksi gas maka semakin berpotensi sistem mengirimkan notifikasi sms ke ponsel pengguna. Hal tersebut kemudian diperjelas dalam tabel kedua, jika tinggi suatu gas yang dideteksi kurang dari 350 maka sistem tidak akan mengirim pesan berupa sms notifikasi namun jika tinggi gas yang terdeteksi lebih dari sama dengan 350 maka sistem akan mengirimkan pesan peringatan ke ponsel pengguna bahwa telah terjadi kebocoran gas.

Grafik Notifikasi SMS menunjukan seberapa tinggi gas yang dideteksi sehingga sistem akan mengirimkan sms peringatan kebocoran gas. Hal tersebut juga tertera dalam grafik pengujian sistem. Grafik pengujian sistem menunjukan banyaknya pengujian yang dilakukan. Dalam pengujian pertama diambil 1 sampel angka yang dianggap sistem tidak dalam status berbahaya sehingga nantinya tidak akan dilakukan pengirima sms notifikasi dan 1 sampel angka yang dianggap sistem berbahaya sehingga akan dilakukan pengiriman sms notifikasi. Hal tersebut dilakukan juga pada pengujian kedua, ketiga dan keempat. 


\section{KESIMPULAN}

Dari penelitian ini, kesimpulan yang bisa diambil adalah:

1. Perkembangan teknologi haruslah dimanfaatkan untuk memberikan alternatif solusi terhadap suatu masalah.

2. Penggunaan jaringan sensor nirkabel memungkinkan pengguna bisa memonitoring sistem dari jauh.

3. Penggunaan layanan short message service membuat pengeluaran biaya lebih hemat dan sedikit.

4. Tingkat ketinggian gas yang terdeteksi akan berpengaruh terhadap pengiriman sms ke ponsel pengguna.

5 .

\section{SARAN}

Dalam penelitian ini hanya menggunakan satu sensor pendeteksi kebocoran gas. Dalam pengembangannya, peneliti menyarankan agar menggunakan tambahan sensor lagi karena jika diimplementasikan ke dalam pabrik atau perusahan yang besar misalnya tentunya satu sensor saja tidak mampu menjangkau luasnya. Maka dari itu, dibutuhkan sensor lebih banyak.

\section{DAFTAR PUSTAKA}

[1] Widyanto, W, and Erlansyah, D, "Rancang Bangun Alat Deteksi Kebocoran Tabung Gas Elpiji Berbasis Arduino," Semantik, vol 4, no 1, 2014.

[2] M. F. Putra, A. H. Kridalaksana, and Z. Arifin, "Rancang Bangun Alat Pendeteksi Kebocoran Gas LPG Dengan Sensor Mq-6 Berbasis Mikrokontroler Melalui Smartphone Android Sebagai Media Informasi," Informatika Mulawarman : Jurnal Ilmiah Ilmu Komputer, vol. 12, no. 1, p. 1, 2017.

[3] Soemarsono, B. E., Listiasri, E and Kusuma, G. C, "Alat Pendeteksi Dini Terhadap Kebocoran Gas LPG," TELE, vol. 13, no. 1, 2016.

[4] Putra, Lucky Yuditia. "Modul Latih Mikrokontroler Arduino Uno untuk Mengontrol Suhu Ruangan dengan Menggunakan Sensor Suhu, Kipas dan Liquid Crystal Display.," Jakarta: Universitas Mercu Buana Jakarta, 2013.

[5] M. O. Buob, A. Lambert, and S. Uhlig, "IBGP2: A scalable iBGP redistribution mechanism leading to optimal routing," Proc. - IEEE INFOCOM, vol. 2016-July, 2016.

[6] Saefullah, A., Syahrial, H., and Santoso, A, "Pendeteksi Kebocoran Tabung Gas Lpg Menggunakan Mikrokontroller At89S2051 Melalui Handphone Sebagai Media Informasi," Semantik vol.1-8, 2012

[7] Kusuma, R. A, "Rancang Bangun Alat Pendeteksi dan Penanggulangan Kebocoran Gas LPG Berbasis Sensor TGS2610," Jurnal Telekontran, vol. 1, no. 1, p. 51-58.

[8] Shrivastava, A. Prabhaker, R. Kumar, R., and Verma, R. "GSM based gas leakage detection system," International Journal of Emerging Trends in Electrical and Electronics, vol. 3, no. 2, 2013.

[9] Ahda, D. A. and Eka Firmansyah, S. T, "Aplikasi Sms Gateway Sebagai Peringatan Kebocoran Gas LPG (Doctoral dissertation, Universitas Gadjah Mada)," 2013. 